\title{
OCORRÊNCIA DO COMPLEXO CARPOPHILUS HUMERALIS (FABRICIUS) - CERATOCYSTIS PARADOXA (De SEYNES) MOREAU EM CANA-DE-AÇÚCAR NO ESTADO DE SÃO PAULO (1)
}

\author{
CARLOS JORGE ROSSETTO $(2,6)$, ANDRÉ LUIZ LOURENÇÃO $(2,6)$, \\ ADEMAR ESPIRONELO $(3,6)$, TOSHIO IGUE $\left(^{4}\right)$ \\ e IVAN JOSÉ ANTUNES RIBEIRO $(5,6)$
}

\begin{abstract}
RESUMO
Foi constatada a ocorrência do besourinho Carpophilus humeralis (Fabricius) (Coleoptera, Nitidulidae) no Estado de São Paulo, em toletes de cana-de-açúcar com podridão-abacaxi, causada pelo fungo Ceratocystis paradoxa (De Seynes) Moreau. Experimento conduzido com duas variedades de cana, IAC64-257 e NA56-79, tratamento do tolete com fungicida e posição da gema no tolete, demonstrou que a variedade NA56-79 respondeu positivamente ao tratamento com fungicida enquanto a variedade IAC64-257 não apresentou resposta. As gemas da extremidade do tolete foram mais afetadas que as centrais.
\end{abstract}

Termos de indexaçāo: Carpophilus humeralis, Ceratocystis paradoxa, cana-de-açúcar, podridâo-abacaxi, Saccharum spp,

(1) Apresentada no XII Congresso Brasileiro de Zoologia, Campinas, SP, 27 de janeiro-1 de fevereiro de 1985. Recebida para publicação em 24 de junho de 1985. (SP).

(2) Seção de Entomologia Fitotécnica, Instituto Agronômico (IAC), Caixa Postal 28, 13001 Campinas

(3) Seção de Cana-de-Açúcar, IAC.

(4) Seçäo de Técnica Experimental e Cálculo, IAC.

(5) Seçâo de Microbiologia Fitotécnica, IAC.

(6) Com bolsa de suplementaçāo do CNPq. 


\section{INTRODUÇÃO}

Em muitas regiões do mundo onde se cultiva a cana-de-açúcar, ocorre uma doença denominada podridão-abacaxi, principal causa do apodrecimento dos toletes e do não-brotamento das gemas (WSMER, 1961). A doença é causada pelo fungo Ceratocystis paradoxa (De Seynes) Moreau, forma perfeita de Thielaviopsis paradoxa (De Seynes) Hoehn. Este fungo vive no solo e estabelece a infecção apenas através de ferimentos, como a extremidade seccionada do tolete, sendo seu desenvolvimento inibido com o início do brotamento da gerra (GALLI et alii, 1980, e WSMER, 1961). Levantamento feito no Estado de São Paulo demcnstrou que $C$. paradoxa é a espécie de fungo mais importante associada à podridão dos toletes e não-brotamento das gemas de cana-de-açúcar (CARVALHO, 1963). A doença aparece comumente quando ocorre um atraso no brotamento, por encharcamento do solo, frio, período seco, plantio profundo e uso de toletes da parte mais velha do colmo (GALLI et alii, 1980, e WSMER, 1961). No Estado de São Paulo, condições desfavoráveis ao brotamento das gemas e, portanto, favoráveis à podridão-abacaxi, ocorrem em plantios tardios de março até agosto (ARRUDA, 1946, e GALLI et alii, 1980).

No Havaí, CHANG \& JENSEN (1974) demonstraram que um besourinho-preto, Carpophilus humeralis (Fabricius) (Coleoptera, Nitidulidae) é vector de C. paradoxa em cana-de-açúcar e que é mais atraído e se desenvolve mais rapidamente em cana já infectada pelo fungo do que em cana sadia. Há uma provável simbiose entre $C$. humeralis e o fungo, já que este favorece o desenvolvimento daquele e o besourinho colabora para disseminar o fungo, transportando esporos em seu corpo (CHANG \& JENSEN, 1974).

C. humeralis alimenta-se de várias espécies de frutos maduros ou em decomposição, além de espigas de milho e grãos armazenados. Esse besourinho pertence ao subgênero Urophorus e é denominado, por alguns autores, de Urophorus humeralis (Fabricius). Oriundo da Europa, foi introduzido neste século no continente americano. Sua ocorrência foi registrada nos EUA, Porto Rico, Havaí, Inglaterra, Líbia, Itália, Tanganica, Egito, Arábia Saudita, Índia, Malásia, Ceilão, Fiji, Filipinas e China (CONNELL, 1981).

A biologia de $C$. humeralis foi estudada em frutos maduros de abacaxizeiro (SCHMIDT, 1935). A fêmea adulta vive em média três meses, sendo que o período de desenvolvimento de ovo a adulto é de três semanas, a $27^{\circ} \mathrm{C}$.

\section{OCORRÊNCIA NO ESTADO DE SÃO PAULO}

Em abril de 1983 , em vista de $80 \%$ de falhas no brotamento, foi perdido ensaio de adubação fosfatada em cana-de-açúcar com a variedade IAC64-257, instalado por pesquisadores do Instituto Agronômico na Destilaria Equipav, no 
município de Promissão. Constatou-se, pelo arrancamento e exame dos toletes, que a baixa porcentagem de brotamento foi devida à doença chamada podridão-abacaxi, causada por $C$. paradoxa. Logo após o plantio, houve assoreamento do sulco, por uma intensa chuva seguida de estiagem -(vinte dias sem chuva), causando um atraso no brotamento e favorecendo a ocorrência da podridão. Os toletes infectados apresentavam no interior uma grande população de larvas e adultos de Carpophilus humeralis (Fabricius) ( $\left.{ }^{7}\right)$. Não foram encontradas pupas no interior dos toletes, o que sugere que elas se formam no solo.

A ocorrência da podridão-abacaxi associada a populações de $C$. humeralis foi também observada em abril de 1983, na mesma região, porém em menor intensidade, em experimentos do Instituto Agronômico instalados na Destilaria Aralco, em Araçatuba, e na Usina Campestre, em Penápolis. Em setembro de 1984, em Araçatuba, outro experimento de variedades de cana-de-açúcar do Instituto Agronômico, na Destilaria Aralco, foi perdido devido à falta de chuva, com ocorrência da podridāo-abacaxi, novamente associada a populações de $C$. humeralis.

Adultos de $C$. humeralis foram incorporados à coleção de insetos da Seção de Entomologia Fitotécnica do Instituto Agronômico de Campinas, sob o número 6783.

\section{INFLUÊNCIA DO TRATAMENTO COM FUNGICIDA, VARIEDADE E POSIÇĀO DAS GEMAS NO TOLETE}

\subsection{Introdução}

No mesmo local do experimento de adubação fosfatada perdido na Destilaria Equipav, em Promissão, foi instalado, em 5 de maio de 1983, ensaio para estudar o efeito de duas variedades, da posição das gemas no tolete e da imersão dos toletes em solução de fungicida, sobre o brotamento das gemas.

\subsection{Material e Métodos}

Numa solução do fungicida Benomil a $1 \%$ de p.a., foram imersos, por um minuto, os toletes a serem tratados. Foram utilizados toletes com três gemas, de duas variedades, NA56-79 e IAC64-257. A parcela consistia em três linhas de cana de $10 \mathrm{~m}$ de comprimento, com 1,40m de espaçamento entre linhas. As duas variedades foram iestadas como subparcelas, cada uma com $5 \mathrm{~m}$ de comprimento. A posição das gemas no tolete constituiu a subsubparcela. Duas gemas

(7) Agradecimentos são devidos ao Dr. W.A. Connell, Systematic Entomology Laboratory, Beneficial Insects Research Laboratory, USDA, Newark, Delaware, USA, pela identificação da espécie do inseto. 
estavam localizadas próximo às extremidades e uma gema na parte central do tolete. $O$ delineamento utilizado foi de parcelas subsubdivididas com oito tratamentos e dezesseis repetiçōes. Os toletes foram distribuídos no sulco à razão de doze gemas por metro, totalizando 60 gemas na subparcela. Em 18 de agosto de 1983, foi feita avaliação das gemas brotadas e não-brotadas nos 20 toletes da linha central da subparcela, sendo os números de gemas brotadas transformados em porcentagens. Havia um total de 20 gemas centrais e 40 gemas nas extremidades dos toletes em cada subparcela. Os dados de porcentagens foram submetidos à análise de variância, utilizando-se os testes $F$ e t para discriminar médias.

\subsection{Resultados e Discussão}

Os resultados estão sumariados no quadro 1 e a análise de variância, no quadro 2.

Observa-se, pelo quadro 2, que houve diferenças significativas ao nível de $5 \%$ para variedades $(V)$, fungicida $(F)$ e posição das gemas no tolete $(P)$. Todas as interações duplas $(F \times V, P \times F, P \times V)$ foram significativas, mostrando que os efeitos de cada fator devem ser estudados em relação a cada um dos demais fatores.

O quadro 3 mostra o desdobramento da interação variedade-fungicida, ou seja, o efeito de variedade sobre tratamento com fungicida. Não houve diferença entre as variedades na ausência do fungicida, mas na sua presença a NA56-79 teve um brotamento superior ao da IAC64-257. As significâncias para os tratamentos fungicida e variedades obtidas na análise da variância (Quadro 2)

QUADRO 1. Porcentagem média de gemas brotadas de toletes de cana resultantes da combinação de fungicida, variedade e posição da gema no tolete (média de 16 repetições). Promissão, SP, 1983

Tratamentos

Posição da gema

Meio

Extremidade

$\%$

$\%$

NA56-79

53,1

32,4

IAC64-257

45,5

36,6

NA56-79 + fungicida

72,4

56,8

IAC64-257 + fungicida

38,9

39,1 
podem ser explicadas por uma ação favorável do fungicida na NA56-79, enquanto este tratamento na IAC64-257 não apresentou efeito. Isso demonstra que uma variedade pode responder favoravelmente ao tratamento com fungicida e, outra, não.

QUADRO 2. Análise da variância das porcentagens de gemas brotadas

\begin{tabular}{lrrrc}
\hline Fontes de variação & G.L. & S.Q. & Q.M. & Teste F \\
\hline Blocos & 15 & 1545 & 103 & 0,4 \\
Fungicida (F) & 1 & 3130 & 3130 & $11,0^{*}$ \\
Erro (a) & 15 & 4273 & 284 & \\
Parcela & & & & \\
\hline & 31 & 8948 & & \\
Variedade (V) & 1 & 5954 & 5954 & $32,4^{*}$ \\
F x V & 1 & 4548 & 4548 & $24,7^{*}$ \\
Erro (b) & 30 & 5513 & 183 & \\
& & & &
\end{tabular}

Subparcela

63

24965

$\begin{array}{lrrrr}\text { Posição (P) } & 1 & 4038 & 4038 & 53,3^{*} \\ \text { P F } & 1 & 402 & 402 & 5,3^{*} \\ \text { P x V } & 1 & 1519 & 1519 & 20,1^{*} \\ \text { P x F X V } & 1 & 31 & 31 & 0,4 \\ \text { Erro (c) } & 60 & 4542 & 75 & \\ & & & & \\ \text { Total } & 127 & 35498 & & \end{array}$

$\mathrm{CVa}=36,1 \% \quad \mathrm{CVb}=29,0 \% \quad \mathrm{CVc}=18,6 \%$

* Significativo ao nível de 5\%.

O quadro 4 apresenta o desdobramento da interação posição das gemas com fungicida. As gemas do meio do tolete em média brotaram significativamente melhor que as da extremidade do tolete com ou sem fungicida, o que se explica pelo fato de o fungo penetrar pelo ferimento da extremidade. Pelo mesmo motivo, o fungicida teve efeito significativo apenas sobre gemas da extremidade.

O quadro 5 mostra o desdobramento da interação posição das gemas no tolete com variedades. O efeito da posição da gema foi significativo ao nivel 
de 5\% só na NA56-79, o que sugere uma provável interação entre tamanho de tolete usado para plantio e variedades de cana, na presença dessa doença. Um tolete de cinco gemas na NA56-79 (três gemas internas e duas laterais) provavelmente teria uma brotação superior a um tolete de três gemas (uma do meio $e$ duas laterais). Na IAC64-257 isso não seria esperado, já que a gema do meio não brotou melhor que a da extremidade.

É provável que o uso de toletes maiores de algumas variedades tenha efeito favorável em plantios sujeitos a essa doença.

QUADRO 3. Porcentagem média de gemas brotadas de duas variedades de cana-de-açúcar na presença $e$ na ausência de fungicida e valores do teste $F$ para discriminar variedades dentro de fungicida e $t$ para discriminar fungicida dentro de variedades (média de 32 repetiçōes). Promissão, SP, 1983

\begin{tabular}{cccr}
\hline Tratamentos & NA56-79 & IAC64-257 & F \\
\hline & $\%$ & $\%$ & \\
Com fungicida & 64,6 & 39,0 & $56,9 *$ \\
Sem fungicida & 42,8 & 41,1 & 0,26 \\
\hline $\mathrm{t}$ & $5,7^{*}$ & 0,5 & \\
\hline
\end{tabular}

* Significativo ao nível de $5 \%$.

QUADRO 4. Porcentagem média de gemas de cana-de-açúcar brotadas de duas posições no tolete, centro e extremidade, na presença e na ausência do fungicida e valores do teste $F$ para discriminar posições dentro de fungicida e $t$ para discriminar fungicida dentro de posiçōes (médias de 32 repetiçōes). Promissão, SP, 1983

\begin{tabular}{cccc}
\hline Tratamentos & Meio & Extremidade & F \\
\hline Com fungicida & 55,6 & $\%$ & \\
Sem fungicida & 49,3 & 48,0 & $12,5^{*}$ \\
\hline $\mathrm{t}$ & 1,9 & 34,5 & $46,2^{*}$ \\
\hline
\end{tabular}

\footnotetext{
* Significativo ao nível de $5 \%$.
} 
QUADRO 5. Porcentagem média de gemas brotadas de duas posiçōes no tolete, centro e extremidade, dentro de variedades, e valores do teste $\mathrm{F}$ para discriminar posiçōes dentro de variedades e t para discriminar variedades dentro de posições (médias de 32 repetiçōes). Promissão, SP, 1983

\begin{tabular}{cccc}
\hline Tratamentos & Centro & Extremidade & F \\
\hline & $\%$ & $\%$ & \\
NA56-79 & 62,7 & 44,6 & $5,4^{*}$ \\
IAC64-257 & 42,2 & 37,9 & 1,3 \\
\hline \multicolumn{1}{c}{$t$} & $6,2 *$ & 2,0 & \\
\hline
\end{tabular}

\footnotetext{
* Signifjcativo ao nível de $5 \%$.
}

\section{SUMMARY}

\section{OCCURRENCE OF THE COMPLEX CARPOPHILUS HUMERALIS (FABRICIUS)- CERATOCYSTIS PARADOXA (De SEYNES) MOREAU IN SUGAR CANE IN THE STATE OF SÄO PAULO, BRAZIL}

The pineapple disease caused by Ceratocystis paradoxa (De Seynes) Moreau has been recognized as the main cause of poor germination of sugar cane fields in the State of São Paulo, Brazil, associated with rottening of the sugar cane cuttings. In 1983 in the counties of Promissāo, Penápolis and Araçatuba and again in 1984 in Araçatuba for the first time was observed the occurrence of the pineapple disease associated with high populations of the nitidulid beetle Carpophilus humeralis (Fabricius). The authors ignore previous records of occurrence of this nitidulid species in Brazil. An experiment with three factors, fungicide treatment, variety and position of the buds in the cutting was performed. The treated cuttings were immersed in a solution of Benomil at $1 \%$ a.i. Two varieties of sugarcane, NA56-79 and IAC64-257 were used. Two positions of the buds in the cuttings were considered, middle and lateral. A split split plot design was used with 8 treatments and 16 replications. The presence or absence of fungicide treatment was the main plot. Varieties were sub plots and position of the buds within the cuttings constituted the sub sub plots. The treatment of the cutting for 1 minute in the fungicide solution improved the germination of the variety NA56-79 but had no effect in the variety IAC64-257. There was no difference between the percent germination of the two varieties in the absence of the fungicide treatment. In general the buds from the middle of the cuttings germinated better than lateral ones what is explained by the entrance of the fungi through the cut tissue, more distant from the middle bud.

Index terms: Carpophilus humeralis, Ceratocystis paradoxa, sugarcane, pineapple disease, Saccharum spp. 


\section{AGRADECIMENTOS}

Agradecimentos são devidos à Destilaria Equipav, Promissão, SP, pelo apoio dado à execução deste trabalho.

\section{REFERÊNCIAS BIBLIOGRÁFICAS}

ARRUDA, S.C. As doenças da cana-de-açúcar no Estado de Sāo Paulo. O Biológico, São Paulo, 12:63-69, 1946.

CARVAlHO, P.C.T. Estudos das podridōes dos toletes de cana-de-açúcar. Piracicaba, E.S.A. "Luiz de Queiroz", 1963. 98p. Tese (Doutoramento)

CHANG, V.C.S. \& JENSEN, L. Transmission of the pineapple disease organism of sugarcane by nitidulid beetles in Hawaii. Journal of Economic Entomology, 67:190-192, 1974.

CONNELL, W.A. Bibliography of Carpophilus humeralis (Fab.) in support of a revision of the genus Carpophilus Stephens. Bulletin of the Entomological Society of America, 27:263-266, 1981.

GALLI, F.; CARVALHO, P.C.T.; TOKESHI, H.; BALMER, E.; KIMATI, H.; CARDOSO, C.O.N.; SALGADO, C.L.; KRÜGNER, T.L.; CARDOSO, E.J.B.N. \& BERGAMIN FILHO, A. Doenças das plantas cultivadas. São Paulo, Ceres, 1980. ن.2.

SCHMIDT, C.T. Biological studies on the nitidulid beetles found in pineapple fields (Nitidulidae, Coleoptera). Annals of the Entomological Society of America, 28:475-511, 1935.

WISMER, C.A. Pineapple disease. In: MARTIN, J.P.; ABBOTT, E.V. \& HUGHES, C.G. Sugar-cane diseases of the world. New York, Elsevier Publishing Company, 1961. v.1, p.222-235. 